\section{INCIDENCIAS FILOSÓFICAS ACTUALES EN LA SOCIEDAD DIGITAL: IDEOLOGÍAS, DESINFORMACIÓN Y CONFUSIÓN EPISTEMOLÓGICA}

\author{
Miguel Palomo \\ Universidad Complutense de Madrid \\ https://orcid.org/0000-0002-0372-1263 \\ mipalomo@ucm.es
}

\begin{abstract}
Cómo citar este artículo/Citation: Palomo, Miguel (2021). Incidencias filosóficas actuales en la sociedad digital: ideologías, desinformación y confusión epistemológica. Arbor, 197(802): a630. https://doi.org/10.3989/arbor.2021.802008
\end{abstract}

Recibido: 30 marzo 2020. Aceptado: 12 mayo 2021.

Publicado: 3 febrero 2022.

RESUMEN: A través de la difusión de elementos informativos (es decir, cualquier ítem creado y difundido con la finalidad de transmitir información) en la sociedad digital, la desinformación modifica 1) la ideología social y política de los usuarios de las redes sociales y de otras herramientas digitales, así como su cosmovisión o conjunto de ideas sobre la realidad; 2) la actuación ética del sujeto en el mundo, lo que incluye actos violentos, terroristas y de terrorismo estocástico; y 3 ) las condiciones de veracidad que se le otorgan a un hecho para etiquetarlo como veraz, lo que deviene en el fenómeno de la confusión epistemológica, mediante el cual se otorga veracidad a un hecho por el mero deseo de que sea verdadero, en lugar de apelar a voces de autoridad reconocida.

PALABRAS CLAVE: Desinformación, noticias falsas, sociedad post-covid, confusión epistemológica.

\section{PHILOSOPHICAL INCIDENCES IN THE DIGITAL SOCIETY: IDEOLOGIES, DISINFORMATION AND EPISTEMOLOGICAL CONFUSION}

Copyright: (C) 2021 CSIC. Este es un artículo de acceso abierto distribuido bajo los términos de la licencia de uso y distribución Creative Commons Reconocimiento 4.0 Internacional (CC BY 4.0).

ABSTRACT: Through the dissemination of informative elements (i.e., any item created and disseminated with the purpose of conveying information) in the digital society, disinformation modifies 1 ) the social and political ideology of users of social networks and other digital tools, as well as their worldview and overall ideas about reality; 2) the ethical behaviour of the subject in the world, which includes violent, terrorist, and stochastic terrorist acts; and 3) the conditions of veracity that are granted to a fact in order to label it as truthful, which results in the phenomenon of epistemological confusion, whereby veracity is granted to a fact just by wishing it to be true, instead of appealing to voices having recognized authority.

KEYWORDS: Disinformation, fake news, post-covid society, epistemological confusion. 


\section{INTRODUCCIÓN}

La proliferación de bulos que han maximizado la incidencia de la COVID-19 en momentos claves de la pandemia de 2020 y sus efectos en el conjunto social ha tenido un impacto directo en distintos ámbitos de la sociedad y en sus relaciones socioeconómicas: ha contribuido a cambiar gobiernos, modificar ideologías y manipular hechos gracias a grupos de agentes que han utilizado herramientas digitales para transmitir todo tipo de desinformación. De este modo, la desinformación ha determinado el funcionamiento y las expectativas de la sociedad post-covid. Se trata solamente de un ejemplo de la forma en la que la sociedad digital se encuentra influenciada por una serie de factores de índole política, pero también ética y filosófica, que encuentran su punto común en la difusión de desinformación y en el funcionamiento de redes sociales y otras herramientas similares.

Este trabajo defiende la hipótesis de que, a través de los elementos o ítems informativos en la sociedad digital, la desinformación modifica 1) la ideología social y política, así como la popularmente denominada cosmovisión o conjunto de ideas que se mantienen sobre la realidad; 2 ) la praxis en el mundo, es decir, la actuación ética del sujeto; y 3) las condiciones de veracidad que se le otorgan a un hecho para etiquetarlo como verdadero. El término elementos informativos hace referencia a cualquier elemento creado con el objetivo de transmitir información. Ejemplos de elementos informativos son las noticias, imágenes (con o sin texto), memes, vídeos multimedia, hipervínculos y otros de carácter similar.

En muchos lugares se ha tratado la importancia que la tecnología digital posee con respecto a nuestro lugar en el mundo. De entre los más destacados, Javier Echeverría realizó la distinción de tres entornos distintos, diferenciados según las formas de organización que la sociedad toma: basada en la naturaleza (primer entorno); basada en la urbanización (segundo entorno); y basadas en las tecnologías de la comunicación e información (tercer entorno) (Echeverría, 1999: 48 y ss.). La importancia de separar los tres entornos radica en la diferenciación ontológica de éstos, siendo el tercer entorno ontológica y estructuralmente diferente a los otros dos. Es precisamente, en este último entorno donde se presenta la problemática en la que se engloba este trabajo. Echeverría señala que el tercer entorno ofrece un mundo autónomo de los otros dos, siendo de creación artificial (diferenciándolo por tanto de los dos primeros entornos, basados en el mundo físico), pero de determinación tan real como los otros. También señala la apariencia de libertad que posee el tercer entorno, que nos retrotrae a la idea primigenia de la ilusión de poseerla (Echeverría, 1999: 395 y ss.). Sin embargo, contrariamente a esta idea, Echeverría muestra que son los «Señores del Aire» (o las grandes corporaciones tecnológicas responsables de la difusión de la mayor parte de información en las redes) los que deciden las reglas del juego, como si de una estructura neofeudal estuviésemos hablando:

El principal problema de la identidad en E3 [tercer entorno] deriva de la posibilidad de que cualquiera manipule algunas de esas representaciones $R_{i}$, lo cual es dificilísimo en E1 [primer entorno] (tomar la apariencia física de una persona) y nada fácil en E2 [segundo entorno], aunque siempre ha habido falsificadores de datos e identidades. En cambio, una vez lanzada una representación $R_{i}$ a E3, su manipulación es muy fácil (Echeverría, 1999: 419-420).

También Ramón Queraltó ha escrito sobre la incidencia de la tecnología en la sociedad, en su caso concretamente refiriéndose sobre la actuación ética. Queraltó señaló que la tecnología posee un carácter propio que le hace incrementar su capacidad transformadora y modificadora de la realidad (Queraltó, 2008: 36), una idea que indica la naturaleza transformadora que pueden llegar a poseer las herramientas digitales en nuestra era; así como que la ética, para resultar útil, debe enfocarse en el sujeto tecnológico ${ }^{1}$.

En este contexto reaparece el debate sobre la neutralidad o no neutralidad de la tecnología en el contexto de la sociedad digital (ver Pérez Sedeño, 2005; Echeverría, 2002; Ruiz Gómez, 2014; Bautista García-Vera, 1994). No podría decirse que internet, el correo electrónico o las redes sociales ocasionen, por ejemplo, cambios ideológicos por sí mismas. Más bien una serie de actores utilizan estas tecnologías para difundir ideas y cosmovisiones que alteran la ideología de la masa social. La diferencia es la naturaleza del entorno en el que se presentan: si bien encontramos muchos casos en la historia de uso de la tecnología para difundir ideas (como por ejemplo, el protestan-

1 Su tesis denominada "caballo de Troya al revés», directamente relacionada con estas cuestiones, viene a explicar que la ética para una racionalidad tecnológica sería vista como un caballo de Troya, aunque constructivo en lugar de destructivo, de ahí la etiqueta «al revés» (Queraltó, 2003). 
tismo a través de la imprenta en la Alemania del siglo $\mathrm{XVI}$ ), el tercer entorno, el cual, sin fronteras físicas existentes y podría decirse que incluso sin frontera ideológica alguna, permite difundir diferentes ideas a millones de personas en lo que se tarda en desbloquear con nuestra huella dactilar un terminal móvil. Por ello, cabe señalar que la diferencia entre el uso de la tecnología antigua, como la imprenta, y la tecnología digital propia del siglo XXI, no radica solamente en la rapidez mediante la cual la información se transmite, sino también la naturaleza de las comunicaciones, el entorno en el que se prestan y el modo en el que se utilizan.

En este sentido, los agentes que determinan el funcionamiento de los algoritmos que a su vez deciden el funcionamiento de diferentes redes sociales y otras herramientas digitales no realizan una propagación activa de los diferentes elementos informativos existentes en la red (como sí fue el caso de la imprenta a la hora de difundir textos), sino que «impulsan la construcción y el mantenimiento del tercer entorno» (Echeverría, 1999: 174). En otras palabras: facilitan el marco tecnológico y las condiciones físicas y virtuales en el que la información se presenta; fomentan el uso de estas redes por los usuarios; y posteriormente deciden qué tipo de información resulta relevante (y por lo tanto visionada con prioridad) para el resto de usuarios ${ }^{2}$. Por ejemplo, en redes como Youtube, Twitter o Tiktok se valora la interacción con ciertos ítems informativos: mientras más interacciones realiza alguien con alguno de esos ítems, la red sugerirá otros de la misma naturaleza al sujeto receptor, fomentando, por tanto, que un usuario se introduzca en redes que retroalimentan pensamientos de un tipo concreto. Esto se ha explicado mediante la noción echo chambers o cámaras de eco, las cuales se definen como «entornos en los que la opinión, la inclinación política o la creencia de los usuarios sobre un tema se refuerza debido a las repetidas interacciones con compañeros o fuentes que tienen tendencias y actitudes similares» (Cinelli et al., 2021: 1). A su vez, la rapidez con la cual se transmiten esos ítems o elementos informativos, junto con la facilidad con la que se difunden por los usuarios que los han recibido originalmente, impide que las diferentes comunidades que poseen autoridad para desmentir informaciones erróneas puedan corregirlas con la misma rapidez. Ello, a su vez, permite que los efectos de la desinformación no sean corregidos, y que la incidencia de los elementos informativos se haga presente en los cambios ideológicos de parte de los usuarios de redes sociales, en su actuación práctica en el mundo y en sus criterios básicos para otorgar veracidad a ciertos elementos informativos sobre otros.

\section{INCIDENCIA IDEOLÓGICA Y POLÍTICA}

Los elementos informativos se crean y se difunden con la finalidad de transmitir información a una serie de sujetos receptores. Estos elementos informativos han existido siempre en diferentes formas: pueden entenderse como elementos informativos artículos de periódico o noticias difundidas a través de televisión o radio. Desde el nacimiento de la world wide web, sin embargo, éstos se adaptan a las nuevas tecnologías disponibles: también son elementos informativos correos electrónicos, noticias en un portal web, banners de anuncios, imágenes, capítulos de podcasts, noticias de un periódico digital, vídeos en redes como Youtube, tweets, memes o cualquier ítem que pretenda transmitir una información concreta a uno o varios sujetos receptores. Si bien antes del uso masivo de internet la creación de elementos informativos era casi exclusividad de periodistas, agencias oficiales y personas con autoridad y reconocimiento público, en la actualidad, y sobre todo desde la aparición de las redes sociales, estos elementos de información pasan a ser creados y a estar a disposición de cualquier usuario de internet, sin distinción entre las figuras de experto e inexperto. Es por ello que el papel principal en la comunicación de elementos informativos en estas herramientas digitales pasa de los agentes generadores de elementos informativos a los mismos espacios difusores, como podrían ser las redes sociales o foros de internet.

No es de extrañar, por tanto, la proliferación de lo que en los últimos años ha venido a denominarse como fake news o noticias falsas, pues este fenómeno tiende a surgir cuando el papel generador de elementos informativos no nace de expertos o sujetos con autoridad socialmente reconocida. Esto ha ocurrido incluso antes de la llegada de internet a la mayoría de hogares, pues en ocasiones ciertos bulos han acabado siendo transmitidos por diferentes medios tradicionales como revistas y periódicos (Ortiz de Guinea y Martín Sáez, 2019: 108). Lo que sí encontramos novedoso en nues-

2 Uno de los pilares más importantes de las herramientas más conocidas de la red (como pueden ser el buscador de Google, los feeds de Facebook e Instagram o los tweets más relevantes de una etiqueta concreta) es el conjunto de algoritmos que deciden la información relevante que será mostrada al sujeto receptor de un modo personalizado. 
tros días, aparte de su rápida difusión en masa a través de las herramientas digitales, es el uso ideológico que se realiza de estos elementos desinformativos (término que se refiere a elementos informativos que buscan provocar desinformación en el sujeto receptor). La elección de esta terminología está relacionada con la filosofía de la información. Según los trabajos de Luciano Floridi, una definición general de la información (GDI) debe entenderse en términos de datos más significado (Floridi, 2011: 83-84). En este sentido, en muchos de estos elementos informativos, la información no siempre se encuentra en las palabras, sino que a veces se transmite únicamente a través de imágenes que son visualmente significativas para los receptores (siguiendo la GDI.3 de la definición tripartita de información de Floridi). Aunque los medios de comunicación suelen hablar de fake news o información falsa, siguiendo la definición de Floridi, la información siempre es válida. Según esta posición no existe la información falsa, sino que debemos referirnos a desinformación, así como a elementos desinformativos.

Algunos de los elementos desinformativos más populares en los últimos años corresponden a aquellos que, por ejemplo, han afirmado que el planeta Tierra es plano. Este fenómeno, que ha tenido mayor peso en redes como Youtube (ver Paolillo, 2018), es un ejemplo de cómo los elementos informativos poseen una incidencia sobre los ámbitos teórico y práctico de la vida de cualquier sujeto que participe en estas redes digitales. ¿Cómo es posible que una serie de elementos desinformativos provoquen tal cambio de cosmovisión en un grupo de sujetos? La respuesta está en que la creación de estos elementos informativos no se presenta aisladamente, sino en un conjunto de elementos informativos que parecen tener la finalidad de empujar a los receptores de éstos hacia un espectro concreto del ámbito ideológico: la desconfianza en el estado, en el sistema público, en las agencias oficiales de información, en las instituciones educativas, científicas o en la veracidad de sus estudios académicos. Todo ello, dentro de diferentes echo chambers, influencia a un tipo de población muy definida que, a la postre, se convierte en un aliado ideológico a la hora de ser traducido en votos en los sistemas democráticos modernos.

Hay que señalar que el proceso de radicalización ideológica de las personas no se suele producir mediante la reflexión pausada y razonada de ciertas ideas. Más bien, suele producirse mediante la llamada a la emoción y a la reacción visceral. Esta es la forma de actuar que tienen, por ejemplo, los grupos radicales islámicos para conseguir que europeos, habitualmente de clase media o baja, dejen sus países para luchar con grupos como el Daesh (Ortega Dolz, 2015). Lo interesante de estos casos es que estos europeos se radicalizan aún habiendo recibido una educación reglada (es decir, normalmente con contenidos de educación en valores o educación inclusiva, entre otros). Esto muestra que la educación, por sí misma, no impide la radicalización a través de la desinformación. Más bien parece indicar la fuerza de estos métodos que buscan la reacción visceral, que no deja de ser la misma metodología que se utiliza en la difusión de elementos desinformativos de diferente tipo. No es muy diferente la desinformación que, durante la pandemia de la COVID-19, ha animado a los usuarios de redes sociales a abstenerse de tomar medidas sanitarias que podrían prevenir o al menos minimizar el número de infecciones y muertes en la población. La conexión entre los bulos y el aumento del número de muertes radica, precisamente, en la difusión de elementos informativos. Aunque no sea necesariamente evidente para sus receptores, los elementos informativos transmiten una serie de pensamientos o puntos de vista ideológicos que buscan cambiar las perspectivas políticas y sociales del sujeto, objetivo que se persigue a menudo con información que tiene un sesgo supuestamente cómico (como es el caso de la mayoría de memes, por ejemplo). Una prueba de este proceso de inculcación la encontramos en los primeros meses tras la aparición de la COVID-19 en Europa, cuando la mayoría de los bulos se centraron en promover la no utilización de medidas sanitarias o en atacar estas medidas para fomentar una reacción emocional y violenta por parte de los ciudadanos (Nguyen y Catalan-Matamoros, 2020). Por señalar otros ejemplos de incidencia similar: es conocido que la difusión de elementos desinformativos en las elecciones brasileñas de 2018 fue clave para el resultado de las votaciones (Isaac y Roose, 2018). También el expresidente de los Estados Unidos de América Donald Trump utilizó la retórica de los elementos desinformativos con la finalidad de construir una imagen pública que, aparte de encauzar el debate político, le beneficiase en los comicios democráticos:

Trump's rejection of criticism as fake news thereby serves as a tool designed to reinforce his carefully crafted identity within the Spectacle: it allows the president to assert the contradiction that he is a renegade, anti-establishment figure despite his existing public persona as an authoritarian capitalist. Trump's 
critique of the mass media should be perceived, therefore, not as a repudiation of the Spectacle in contemporary society; instead, it should be considered as an act purposefully designed to contribute to his erroneous portrayal as an anti-establishment figure and reinforce his position as a central member of the American sociopolitical milieu (Bleakley, 2018: 428).

Como podemos comprobar, la radicalización ideológica de los receptores de elementos desinformativos se presenta junto con un cambio de cosmovisión de la realidad en la que se encuentran como sujetos activos. Hasta tal punto es así que, en muchos de estos casos, lo que podría parecer una mera defensa de ideologías políticas ha devenido en el uso activo de la violencia por parte de los sujetos receptores. No es casualidad que tan sólo en el año 2019, sujetos radicalizados en internet gracias al consumo masivo de elementos desinformativos hayan acabado con la vida de varias decenas de personas ${ }^{3}$. Por todo ello, es razonable defender que la difusión de estos elementos desinformativos conlleva también la difusión de una cosmovisión o comprensión de la realidad que no se habría dado de no ser por el interés ideológico de sus creadores y difusores.

\section{INCIDENCIA ÉTICA O EN LA ACTUACIÓN DEL SUJE- TO EN EL MUNDO}

Si bien primeramente hemos hablado de una apología con un marcado cariz ideológico a través de la creación y difusión de elementos desinformativos, en algunos casos esta defensa de ideas pasa a la práctica. Ejemplo de ello es el fenómeno que ha sido denominado "terrorismo estocástico», noción que viene a señalar actos de terrorismo llevados a cabo por lobos solitarios que han sido alimentados con elementos informativos que refuerzan continuamente la ideología radical que han ido adquiriendo paulatinamente gracias a la desinformación, al funcionamiento de las redes y a las echo chambers (Hamm y Spaaij, 2017: 84 y ss.). Uno de los casos más conocidos es el atentado de dos mezquitas en la ciudad de Christchurch en Nueva Zelanda que tuvo lugar el 15 de marzo de 2019. El autor de las cincuenta y una muertes fue un internauta radicalizado en el tablón de internet 8chan, donde llegó a exponer, con anterioridad a los ataques, un manifiesto de setenta y cuatro páginas Ilamado «The Great
Replacement» (El gran reemplazo), título que hace referencia a diferentes teorías sobre el supuesto genocidio de los sujetos de raza blanca, y donde se señala que la población inmigrante que habita Europa está invadiendo el continente y deben ser erradicados, entre otros asuntos (ver Önnerfors, 2019).

Para comprender este proceso de radicalización que da pie a al terrorismo estocástico debemos hacer referencia al funcionamiento de algunos de los lugares comunes de radicalización. El tablón 8chan (similar a un foro de internet) surge de otro tablón, 4chan, famoso por la casi ausente falta de control sobre el contenido que los usuarios suben al tablero, el cual es siempre anónimo y automáticamente borrado conforme éstos generan nuevo contenido. Los usuarios de 4chan son responsables de algunos de los memes más conocidos de la era de internet, los cuales son compartidos según la disposición del tablero, que se organiza por hilos o subtablones (ver Nissenbaum y Shifman, 2015: 487-488). En uno de ellos, el hilo random o /b/, de temática libre, se concentran todo tipo de elementos informativos generados por los usuarios sin apenas restricción. Es en este lugar donde surgen todo tipo de memes que podrían identificarse ideológicamente de corte radical, como por ejemplo colocar la esvástica nazi como el término más buscado en el motor de búsqueda de Google. Si bien el contenido del hilo random de 4chan puede considerarse como ideológicamente radical, 8chan es el tablón donde recala gran número de los usuarios de 4chan tras una discusión sobre el gamergate (Ollero, 2019). 8chan, creado en 2013, solamente tiene una norma: eliminar enlaces con contenidos protegidos en Estados Unidos (tales como películas o grabaciones musicales); el resto, está todo permitido. Es el lugar digital donde se albergó, por ejemplo, el vídeo con el tiroteo del autor de la matanza de Christchurch, y el lugar donde se había radicalizado durante años.

La matanza de Christchurch es un claro ejemplo de terrorismo estocástico. Un sujeto considerado normal entre sus conocidos que se radicaliza en foros de internet mediante una serie de elementos desinformativos (memes, en este caso) que tienen un alto poder de sugestión ideológica. El consumo masivo de este tipo de elementos informativos, así como el sentimiento de comunidad que genera la pertenencia a

3 Como por ejemplo, la matanza de El Paso, Texas, en agosto de 2019, en las que Patrick Crusius asesinó a veintidós personas tras hacer pública una declaración anti-inmigración en 8chan donde explicaba la ideología que le llevaba a realizar dicha matanza; la matanza de Christchurch que tuvo lugar en Marzo de 2019; y, por último, el tiroteo realizado en abril de 2019 en una siganoga en San Diego, California, por parte de un joven de 19 años que alababa la matanza de Christchurch y arremetía en internet contra los judíos. 
este tipo de foros o tableros, hace surgir una ideología racista que finalmente deriva en un acto terrorista. Es el paso de la ideología teórica y una visión concreta del ser humano, del estado de la sociedad y del mundo que acaba llevando al sujeto a la acción violenta. El terrorismo estocástico, a su vez, es muestra de cómo las herramientas digitales ocasionan cambios éticos en los usuarios o sujetos receptores y consumidores de elementos informativos creados y difundidos con la finalidad de modificar la ideología de los usuarios.

\section{INCIDENCIA EN LAS CONDICIONES DE VERACI- DAD PARA APREHENDER HECHOS}

Los elementos desinformativos han facilitado la eliminación de la frontera entre los hechos veraces o falsos en el ámbito popular. Es decir, encontramos una modificación de las condiciones de veracidad que se deriva del consumo de estos elementos desinformativos. Si bien los criterios tradicionales de verificación de hechos e informaciones no son perfectos, conllevan un consenso que muestra, con un fuerte indicio, la veracidad de un hecho. Sin embargo, estos criterios tradicionales quedan sustituidos por la elección que realiza el sujeto en base a la información contenida en los elementos informativos que se reciben y que son generados en distintos lugares de internet. Es por ello que la categoría de verdad y su significado en la sociedad digital se ha debilitado, lo cual es una muestra clara del fenómeno de la posverdad. En el contexto de la sociedad digital, la aprehensión de lo que es veraz o falso no parece depender de la corroboración con los medios tradicionales que hasta el momento han tenido autoridad para proferir verdades (como por ejemplo, periodistas o instituciones oficiales), sino de la misma elección del sujeto receptor (ver Bermúdez, 2019). Unos elementos informativos se etiquetan como verdaderos según el deseo de verdad que se posea o según reflejen ideas que anteriormente el sujeto defiende como verdaderas, más que por su veracidad misma (Nicolás, 2019: 308 y ss.). Por ello, el deseo de verdad se convierte en una categoría superior a la de las condiciones de verdad, determinando definitivamente lo que para nuestra comprensión es y debe ser lo verdadero y lo falso. Por ello, del mismo modo, los factores y criterios que nos permiten corroborar qué es lo verdadero y lo falso son modificados. Un caso de discusión habitual en multitud de lugares digitales puede servir de ejemplo. Si bien anteriormente la proposición: las Torres Gemelas fueron atacadas por un grupo terrorista el 11-S, está definida por su aparición y defensa en noticiarios y periódicos relevantes a nivel internacional, será más veraz la proposición: la caída de las Torres Gemelas es un complot de judíos estadounidenses, una vez comparada con el marco que los agentes generadores de elementos informativos han ido creando a nuestro alrededor, alimentado, en el caso señalado, por una ideología antisemita y paranoica que defiende hechos ocultados por gobiernos o bulos similares.

Por todo ello, vemos que la proliferación de elementos desinformativos y su utilización por parte de los usuarios de las redes genera el fenómeno denominado «confusión epistemológica» (Palomo, 2021) en los sujetos consumidores de elementos informativos en la sociedad digital, término que hace referencia a la confusión por parte del sujeto de las condiciones de veracidad de un hecho, las cuales ya no dependen de criterios tradicionales de verificación, sino más bien del deseo del mismo sujeto de que ciertos hechos sean verdad.

\section{PENSAMIENTO CRÍTICO EN LA SOCIEDAD DIGITAL}

Una forma de solventar algunos de los problemas causados por los cambios señalados en las secciones anteriores es la formación en pensamiento crítico. Esta formación provee de una serie de herramientas y desarrollos de aptitudes que facilitan que los sujetos receptores de elementos informativos sean capaces de considerar la adecuación de éstos ante el marco teórico y la cosmovisión que poseen. Es evidente que la filosofía es la única disciplina que puede ejercer este papel formativo. Con una formación adecuada en pensamiento crítico se podrá comprender de qué modo algunos de estos elementos informativos o desinformativos buscan empujar al sujeto receptor a la radicalización de su ideología o a la modificación de su pensamiento para el beneficio de terceros. Sin embargo, una limitación de esta propuesta es que la presencia de elementos desinformativos en la sociedad digital es de tal magnitud que incluso aquellas personas que deben ejercer como voces de autoridad pueden acabar sometidas a la desinformación. Parte de este hecho se explica porque, si bien es sencillo reconocer la clara intención ideológica en algunos elementos informativos, es muy difícil reconocerla en su totalidad cuando esta intención se presenta de un modo muy indirecto en un elemento informativo concreto, tal y como es el caso de gran cantidad de memes, que nacen como bromas pero contienen claros elementos políticos o ideológicos indirectos (Ruiz Martínez, 2018: 996). Una segunda limitación de esta 
propuesta es que, si bien idealmente un proceso educativo de calidad debería facilitar que los discentes alcancen competencias que les permitan no caer en este tipo de manipulación ideológica, los procesos de difusión de elementos desinformativos en el entorno digital moldean el marco teórico que a posteriori permite adquirir competencias y objetivos en el mismo proceso educativo. Por ello, es posible que éstos acaben siendo preeminentes y, precisamente por ello, moldeen la manera en la que se recibirán y adquirirán competencias.

La búsqueda de soluciones ante el fenómeno de la desinformación debería ser un asunto de urgencia para los estados democráticos, pues se ha convertido en una herramienta habitual para conseguir todo tipo de fines: actualmente, tanto partidos políticos como fundaciones, Think Tanks, empresas, o incluso trolls de internet utilizan elementos desinformativos para dirigir la opinión pública y la práctica de los sujetos receptores (Westerlund, 2019). A ello hay que añadir que no hay motivos para no pensar que en el futuro próximo estos agentes y entidades utilicen nuevas ramificaciones de la tecnología digital para seguir modificando la ideología y la cosmovisión de los sujetos receptores. Un ejemplo claro lo encontramos en una herramienta que todavía debe desarrollar su máximo potencial, los deepfakes, los cuales poseen un alto poder de sugestión en los sujetos receptores. Se trata de un elemento multimedia en formato vídeo que se genera mediante una serie de algoritmos de inteligencia artificial, los cuales, basándose en metraje existente que muestre la grabación del rostro de una persona (a más metraje, más sencilla será la tarea y más real parecerá el resultado), son capaces de sustituir a la persona del vídeo original por aquella de la que tenemos metraje en vídeo: se trata, por tanto, de sustituir a una persona por otra, colocando en un contexto a alguien que originalmente no estaba en él. Por decirlo de un modo más sencillo: mediante esta herramienta digital se puede realizar un tipo de fotomontaje, colocando a alguien que no estaba en la fotografía, pero en formato vídeo y audio. Con la aparición de deepfakes de apariencia cada vez más veraz, se conseguirá que el sujeto desconfíe incluso en imágenes en vídeo. Ello conlleva que, en el futuro, imágenes en movimiento que no han sido susceptibles de haber sufrido modificación alguna serán puestas en duda por la mera existencia de otras imágenes en movimiento, modificadas o deepfakes, por lo que el grado de veracidad de las imágenes en movimiento se podrá ver reducido drásticamente.

\section{CONCLUSIONES}

El fenómeno de la desinformación ha ocasionado en los últimos años una serie de cambios que sobrepasan el ámbito político para alcanzar también un ámbito filosófico. Primeramente, observamos un cambio ideológico, pues podemos comprobar cómo sujetos receptores de elementos desinformativos que promueven ideologías radicales en diversas redes sociales y foros de internet (como podrían ser el terraplanismo o el antisemitismo) han modificado su visión de la realidad (o cosmovisión) en base al consumo de elementos desinformativos en el marco de las echo chambers.

Encontramos también un cambio perteneciente a la esfera de lo ético. Multitud de sujetos radicalizados en las redes han visto modificada no solamente sus ideas teóricas, sino también su práctica, derivando en multitud de ocasiones en actos de violencia extrema. Es el caso de actos de terrorismo estocástico, término que define diversos actos violentos realizados por lobos solitarios, pero que han sido alimentados por elementos desinformativos en la sociedad digital.

El tercero y último es un cambio que incide en el fenómeno de la confusión epistemológica. El funcionamiento de estas herramientas digitales fomenta que los usuarios acaben en echo chambers donde se comparte un pensamiento que retroalimenta la desinformación y la radicalización ideológica. En este sentido, el marco en el que se presentan emisores y difusores de elementos desinformativos acaba siendo más relevante que aquellas figuras de autoridad socialmente reconocidas a la hora de etiquetar como veraz la información recibida. Es por ello que, en última instancia, el sujeto receptor otorga veracidad a ciertos elementos desinformativos, incluso en ocasiones siendo conscientes de su falta de veracidad, por tal de defender una ideología concreta. Por tanto, las condiciones de veracidad de un hecho dejan de depender de criterios tradicionales de verificación, para estar dominados por el deseo del mismo sujeto receptor.

La incidencia provocada por la difusión de elementos desinformativos es resultado del funcionamiento del marco tecnológico y de las condiciones físicas y virtuales en las que se presenta nuestro ser tecnológico. Hasta tal punto es así, que el estado de la cuestión facilitará que estas incidencias que se introducen en realidades éticas y epistemológicas sigan en aumento. Ejemplo de ello son herramientas digitales, como por ejemplo los deepfakes, que todavía poseen un enor- 
me potencial por desarrollar. Mediante herramientas de este tipo será cada vez más real la idea de que en el tercer entorno no existen hechos veraces o certeros, sino interpretables, según el marco teórico e ideológico en el que se sitúe el sujeto receptor, lo cual es parte del fenómeno de la posverdad.

\section{AGRADECIMIENTOS}

Adscrito al proyecto PAIDESOC (ref. FFI2017-82535-P) y al proyecto Deduktion (ref. UCM-PR65/19-22446).

\section{REFERENCIAS}

Bautista García-Vera, Antonio (1994). EI papel de los intelectuales y la no neutralidad de la tecnología: razones para unos usos críticos de los recursos en la enseñanza. Revista de educación, 303: 243-258.

Bermúdez Vázquez, Manuel (2019). Análisis del concepto "posverdad" desde la óptica de la retórica clásica. Diálogo filosófico, 105: 341-352.

Bleakley, Paul (2018). Situationism and the recuperation of an ideology in the era of Trump, fake news and post-truth politics. Capital \& Class, 42 (3): 419-434. https://doi. org/10.1177/0309816818759231

Cinelli, Mateo; Morales, Gianmarco; Galeazzi, Alessandro; Quattrociocchi, Walter y Starnini, Michele (2021). The echo chamber effect on social media. PNAS March 2, 118 (9): e2023301118. https://doi. org/10.1073/pnas.2023301118

Echeverría, Javier (1999). Los señores del aire: Telépolis y el tercer entorno. Barcelona: Ediciones Destino.

Echeverría, Javier (2002). Ciencia y valores. Barcelona: Ediciones Destino.

Floridi, Luciano (2011). The Philosophy of Information. Oxford: Oxford University Press. https://doi.org/10.1093/acprof:oso/9780199232383.001.0001

Hamm, Mark S. y Spaaij, Ramón. (2017). The Age of Lone Wolf Terrorism. Nueva York: Columbia University Press. https://doi.org/10.7312/hamm18174

Isaac, Mike y Roose, Kevin (2018). Las noticias falsas inundan WhatsApp en Brasil. The New York Times. Disponible en https://www.nytimes.com/ es/2018/10/23/espanol/brasil-whatsa- pp-noticias-falsas.html (consultado el 01-09-2021).

Nguyen, An y Catalan-Matamoros, Daniel (2020). Digital Mis/Disinformation and Public Engagement with Health and Science Controversies: Fresh Perspectives from Covid-19. Media and Communication, 8 (2): 323-328. https://doi. org/10.17645/mac.v8i2.3352

Nicolás, Juan Antonio (2019). Posverdad: cartografía de un fenómeno completo. Diálogo filosófico, 105: 302-340.

Nissenbaum, Asafy Shifman, Limor (2015). Internet memes as contested cultural capital: The case of 4chan's /b/ board. New Media \& Society, 19 (4): 483-501. https:// doi.org/10.1177/1461444815609313

Ollero, Daniel J. (2019). Así es 8Chan, la web proscrita en la que los asesinos de masas cuelgan sus manifiestos. EI mundo. Disponible en: https://www. elmundo.es/tecnologia/2019/08/07/ 5d49b7dbfc6c832a328b4611.html (consultado el 01-09-2021).

Önnerfors, Andreas (18 de marzo de 2019). 'The Great Replacement': Decoding the Christchurch Terrorist Manifesto. Centre For The Analysis of The Radical Right. Disponible en https://www. radicalrightanalysis.com/2019/03/18/ the-great-replacement-decoding-thechristchurch-terrorist-manifesto/ [fecha de publicación, 18-03-2019; fecha de consulta, 01-09-2021]

Ortega Dolz, Patricia (2015). El Estado Islámico tiene 46.000 cuentas en Twitter. El país. Disponible en https://elpais. com/politica/2015/07/24/actualidad/1437753480_585841.html (consultado el 01-09-2021).

Ortiz de Guinea Ayala, Yolanda y Martín Sáez, José Luis (2019). De los bulos a las fake news. Periodismo, contenidos generados por el usuario y redes sociales. Creatividad y sociedad: revista de la asociación para la creatividad, 30: 104-124.

Palomo, Miguel (2021). How disinformation kills: philosophical challenges in the post-Covid society. History and Philosophy of the Life Sciences, 43 (51). https://doi.org/10.1007/s40656-02100408-4

Paolillo, John C. (2018). The Flat Earth phenomenon on YouTube. First Monday, 23 (12). https://doi.org/10.5210/ fm.v23i12.8251

Pérez Sedeño, Eulalia (2005). Las ligaduras de Ulises o la supuesta neutralidad valorativa de la ciencia y la tecnología. Arbor: Ciencia, pensamiento y cultura, 181 (716): 447-462. https://doi. org/10.3989/arbor.2005.i716.402

Queraltó, Ramón (2003). Ética, tecnología y valores en la sociedad global: el caballo de Troya al revés. Madrid: Tecnos.

Queraltó, Ramón (2008). La estrategia de Ulises o ética para una sociedad tecnológica. Sevilla: Doss.

Ruiz Gómez, Luis (2014). Neutralidad de red y desarrollo de las TIC. RUE: Revista universitaria europea, 20: 73-90.

Ruiz Martínez, José Manuel (2018). Una aproximación retórica a los memes de internet. Revista Signa, 27: 9951021. https://doi.org/10.5944/signa. vol27.2018.21856

Westerlund, Mika (2019). The Emergence of Deepfake Technology: A Review. Technology Innovation Management Review, 9 (11): 39-52. https://doi. org/10.22215/timreview/1282 